\title{
STRENGTH CHARACTERISTICS OF CONCRETE CONTAINING POST CONSUMER METALIZED PLASTIC WASTE
}

\author{
Ankur Bhogayata ${ }^{1}$, N.K.Arora ${ }^{2}$, Abhay Nakum ${ }^{3}$ \\ ${ }^{I}$ Associate professor, Dept. of civil engineering, Marwadi education foundation, Rajkot, Gujarat, India \\ ${ }_{2}^{2}$ Principal, L.E. college, Morbi, Gujarat, India \\ ${ }^{3}$ Assistant professor, Dept. of civil engineering, Marwadi education foundation, Rajkot, Gujarat, India
}

\begin{abstract}
This paper represents results of strength tests conducted on concrete containing flakes of waste metalized plastics. The feasibility of post consumer plastic waste (PCMPW) was determined on the bases of tests results of compressive strength and split tensile strength. Ever increasing generation of PCMPW has raised littering issues and has become one of the major sources for landfills. The objective of the test program was to check the feasibility of PCMPW as concrete constituent and possible way of mitigating the environmental impacts occurring from insufficient and unsafe management of PCMPW. The strength tests were performed with three sizes of PCMPW in flaks and fiber form. PCMPW was added in the mixes with 0\%, 0.5\%, 1\%, 1.5\% and 2\% by volume of concrete mix. Test results reveled that strengths reduced with increased PCMPW flakes contents. However, up to $1 \%$ of addition of flakes the strength reduction was negligible for all flak sizes. Moreover, the PCMPW fiber with $1 \mathrm{mmx} 17 \mathrm{~mm}$ size improved the split tensile strength. Experimental results of compressive -split tensile strength were correlated by a standard analytical model and exhibited good agreement with the experimental results. Such concrete could be utilized in pavements, substructural components and in non-structural members.
\end{abstract}

Key Words: Post consumer metalized plastic waste, Concrete, Compressive strength, Split tensile strength, Slump, Compaction factor.

\section{INTRODUCTION}

Use of plastic wastes in concrete has provided an innovative way of safe disposal alternative. Experimental work could be found in literature wherein the feasibility and effects of addition of waste plastics have been carried out by many researchers $[3,5]$.

Plastic waste resulting from various post consumer activities has been a major source of pollution and specifically major littering cause [7]. Food packaging industries have been using metalized plastic in most of the products. Such wastes are found difficult to treat for recycling and re-use. Even in present time, most of such food packaging plastics are disposed as a part of landfill. Landfill on the other hand, raises environmental and socio-economical issues [7].

Researchers therefore have used post consumer plastic wastes in concretes. It has been found that use of PET bottles have been utilized in most of the works. In many of the cases the addition of PET bottles in various forms like flakes and aggregates provided feasibility of plastic waste utilization [6,8,9]. However, negligible work has been carried out on use of metalized plastics - used for food packaging- as concrete constituent.

The present work focuses the feasibility of addition of metalized plastics used in different food packaging. Metalized post consumer plastic films were shredded into flakes of different sizes and added in the concrete mix in different proportions. Workability and basic strength properties namely compressive and split tensile strength of concrete were investigated. Analytical relationship between strengths was obtained. The results demonstrated that in all test conditions the concrete containing metalized waste plastic maintained strength properties up to $70 \%$ at $1 \%$ dosage of plastic flakes. Such novel concrete could preferably used in secondary structural elements and pavements. The experimental program showed potential towards the use of metalized plastic in cement concrete as an alternative way of mitigating the disposal challenges.

\section{RESEARCH SIGNIFICANCE}

PET bottle wastes have been utilized by many researchers towards making the concrete sustainable. Plastic wastes resulting from the post consumer activities, especially from food packaging contributes to the littering and landfill issues due to the fact that such plastics could not be effectively utilized for recycling or re-use. Therefore the principal objective of this study was to check the feasibility of use of waste metalized plastic as concrete constituent. The results of tests on concrete containing different plastic waste contents and sizes were utilized towards predicting the effective use of waste plastic as concrete constituents.

\section{EXPERIMENTAL PROGRAM}

\subsection{Materials, mixes and casting}

Ordinary Portland cement (OPC) of 53-grade normally used in conventional concrete was used to produce the concrete mix. Locally available aggregates of $20 \mathrm{~mm}$ and $10 \mathrm{~mm}$ sizes with ordinary river sand were used. Metalized plastic film 
was received from the local manufacturer. The film was shredded in three different sizes in flake form. The general properties of metalized plastic films are tabulated in Table 1. Three mixes were prepared with different sizes and proportions of waste plastic flakes as shown in table 2 . The water to cement ratio was maintained at 0.45 for all mixes. Plastic films were shredded into three different sizes in flakes form as shown in figure 1 . The average flake size was $1 \mathrm{~mm}, 5 \mathrm{~mm}$ and $17 \mathrm{~mm}$ respectively. The mix proportions of concrete constituents are shown in table 3.

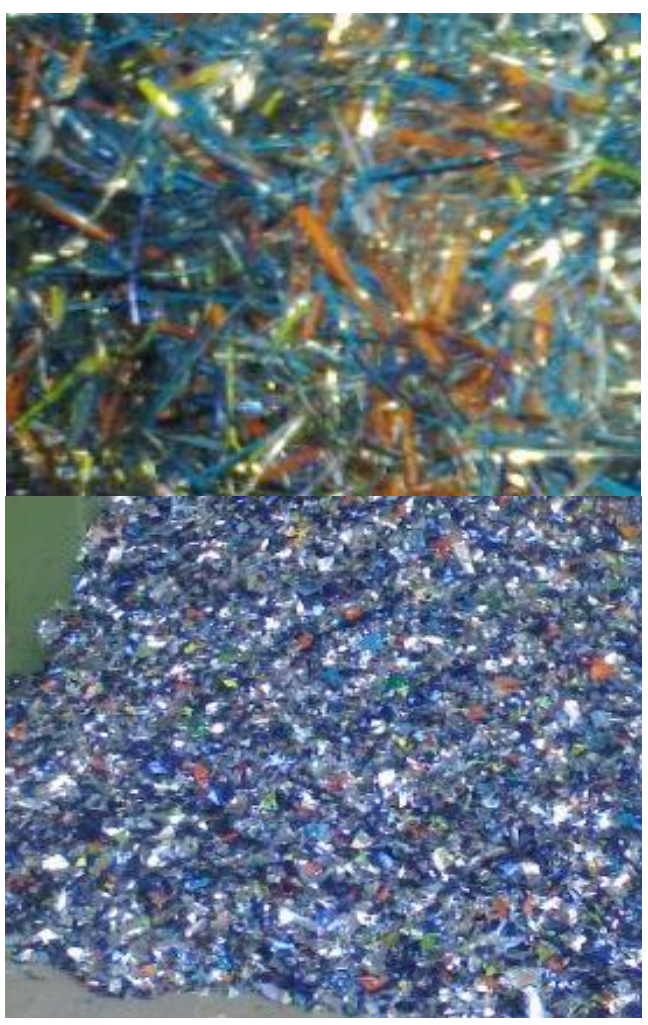

Fig.-1 Shredded PCMPW flakes

Table -1: Properties of PCMPW films

\begin{tabular}{lll}
\hline Property & Value & Unit \\
\hline Resin category & Polythene & -- \\
Plastic type & LDPE & -- \\
Density range & $0.94-1.4$ & $\mathrm{gm} / \mathrm{cm}^{3}$ \\
Thickness & 0.05 & $\mathrm{~mm}$ \\
Tensile strength & $1800-1900$ & $\mathrm{~kg} / \mathrm{cm}^{3}$ \\
& & \\
Elongation & $90-110$ & $\%$ \\
\hline
\end{tabular}

Table -2: Mix proportions

\begin{tabular}{ccc}
\hline Mix & Flake size mm & Flake contents \% \\
Mix 1 & 1 & $0,0.5,1,1.5,2$ \\
Mix 2 & 5 & $0,0.5,1,1.5,2$ \\
Mix 3 & 17 & $0,0.5,1,1.5,2$ \\
\hline
\end{tabular}

Table -3: Concrete mix proportions

\begin{tabular}{|c|c|c|c|c|c|}
\hline $\begin{array}{c}\text { Mix } \\
\mathrm{m}^{3}\end{array}$ & $\begin{array}{c}\text { Cement } \\
\mathrm{kg}\end{array}$ & $\begin{array}{c}\text { Water } \\
\mathrm{L}\end{array}$ & $\begin{array}{c}\text { Sand } \\
\mathrm{kg}\end{array}$ & $\begin{array}{c}\text { Agg. } \\
20 \mathrm{~mm} \\
\mathrm{~kg}\end{array}$ & $\begin{array}{c}\text { Agg. } \\
10 \mathrm{~mm} \\
\mathrm{~kg}\end{array}$ \\
\hline 1 & 383 & 202.5 & 644.4 & 744 & 496 \\
\hline
\end{tabular}

Total $30 \quad$ specimens were casted with $150 \mathrm{mmx} 150 \mathrm{~mm} \times 150 \mathrm{~mm}$ standard cube molds and $150 \mathrm{~mm}$ diameter with $300 \mathrm{~mm}$ height of cylinder molds. Utmost care was taken during the entire process of mixing and casting of the specimens. The specimens were casted for 28 days in potable water and tested in the UTM as per the standard guide lines.

\subsection{Testing}

The specimens were tested for obtaining compressive strength and split tensile strength. The compression testing machine of $2000 \mathrm{KN}$ capacity was used. Figure 3 shows specimens under testing conditions. Fresh concrete mixes were utilized to determine the slump and compaction factor. Fresh behavior of the mixes containing plastic flakes was studied by measuring the slump as in the form of workability and consistency of mix was studied by obtaining the compaction factor of the mixes.

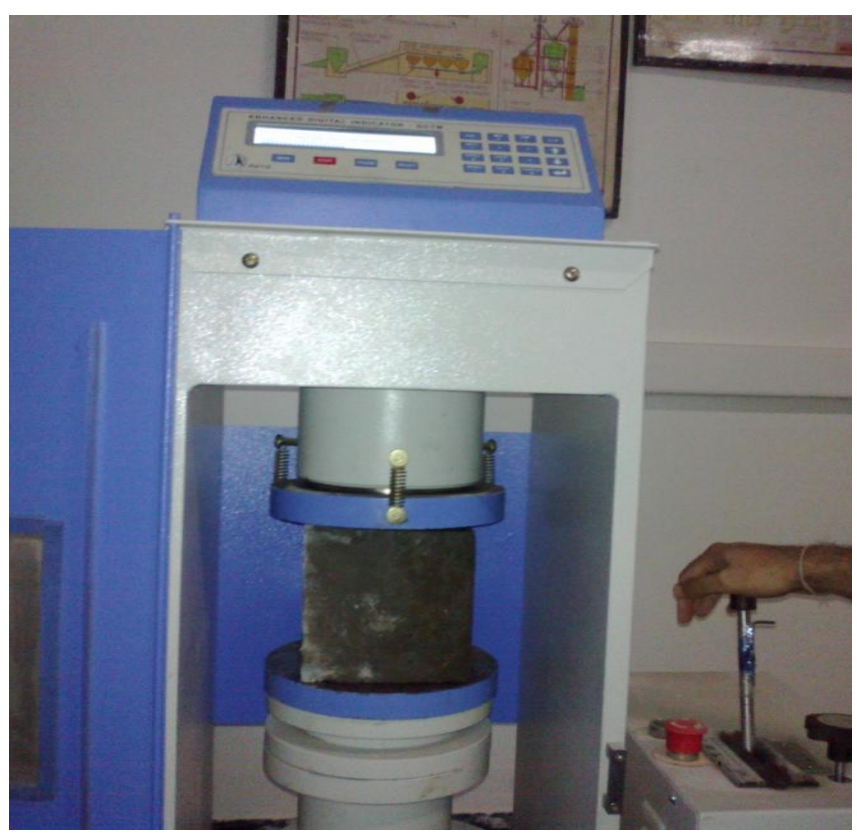

Fig. - 2 Compressive strength apparatus 


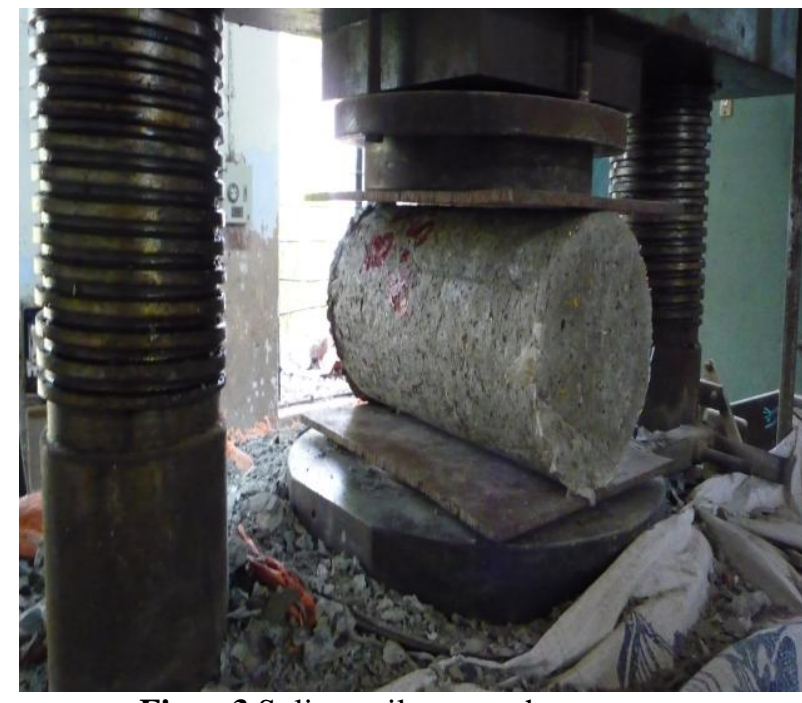

Fig. - 3 Split tensile strength apparatus

\section{RESUTLS AND DISCUSSION}

\subsection{Fresh properties of concrete mixes}

Table 4 summarizes the slump and compaction factor test results. The effects of addition of plastic flakes were studied from the fresh behavior of mixes.

It was observed that the slump and compaction factor values reduced with the addition of the plastic flakes. However the reduction scenario found to be different for slump and compaction factor with the variation in the size and content of the plastic flakes. Addition of flakes in varying sizes reduced the slump up to $30 \%$ at full dosage of $2 \%$. The slump indicates the workability of the concrete mix. Knowing the fact that workability largely depends on the water to cement ratio of a mix, the cement paste in the concrete found responsible for the workable concrete mix. Inclusion of flakes interrupted the sufficient paste formation in the mix as observed and resulted in the stiff and reduced workability of the concrete mixes.

Table 4: Slump and compaction factor results

\begin{tabular}{|c|c|c|c|}
\hline $\begin{array}{c}\text { Batch } \\
\text { no. }\end{array}$ & $\begin{array}{c}\text { Percentage of plastic waste } \\
\text { flakes }\end{array}$ & $\begin{array}{c}\text { Slump } \\
(\mathrm{mm})\end{array}$ & $\begin{array}{c}\text { Compaction } \\
\text { factor }\end{array}$ \\
\hline 1 & $0 \%$ plastic flakes & 86 & 0.91 \\
2 & $0.5 \%$ plastic flakes & 75 & 0.88 \\
3 & $1 \%$ plastic flakes $1 \mathrm{~mm}$ & 58 & 0.85 \\
4 & $1.5 \%$ plastic flakes & 48 & 0.82 \\
5 & $2 \%$ plastic flakes $1 \mathrm{~mm}$ & 35 & 0.73 \\
6 & 0.5 plastic flakes $5 \mathrm{~mm}$ & 70 & 0.85 \\
7 & $1 \%$ plastic flakes $5 \mathrm{~mm}$ & 45 & 0.82 \\
8 & $1.5 \%$ plastic flakes & 36 & 0.76 \\
9 & $2 \%$ plastic flakes $5 \mathrm{~mm}$ & 25 & 0.69 \\
10 & $0.5 \%$ plastic fibre & 68 & 0.89 \\
11 & $1 \%$ plastic fibre $17 \mathrm{~mm}$ & 56 & 0.86 \\
12 & $1.5 \%$ plastic fibre & 43 & 0.77 \\
13 & $2 \%$ plastic fibre $17 \mathrm{~mm}$ & 32 & 0.71 \\
\hline
\end{tabular}

Compaction factor measures the degree of compaction of a mix. A workable concrete generally provides compaction up to the satisfactory level. Plastic flakes have been nonreactive to water and any other constituents in the concrete mix. Possessing very less thickness of $0.05 \mathrm{~mm}$, the presence of the flakes did not affect the compaction characteristics as in the case of slump. The concrete possessing the flakes of varying sizes found compactable up to the acceptable degree. This could be found from the results of tests performed on various mixes as shown in table 4 .

It was observed that with the increased size of waste plastic flakes the slump was reduced rapidly for all contents of flakes. There was a gradual reduction noticed with the increased size of flakes in the slump values with the increased dosage of flakes. Results of slump revealed that with full dosage of waste plastic flakes of $2 \%$ by volume of mix provided acceptable range of workability and could be utilized for pavements and hand compacted concrete used in foundations. Similarly for compaction factor found to be in between 0.69 to 0.88 with varying flakes content provided acceptable degree of compaction showing the maximum reduction up to $24 \%$ at full flakes dosage.

\subsection{Strength properties hardened concrete}

Figure 4 shows average value of compressive strength and figure 5 shows split tensile strength of concrete containing varying proportions and sizes of waste plastic flakes. Results showed reduction in compressive strength with the increased flakes content with the varying sizes. Addition of flakes reduced the strength up to $30 \%$ for full dosage of flakes as $2 \%$ by volume.

\subsubsection{Compressive strength}

Compressive strength was affected by addition of plastic waste flakes and showed reduction with increased flakes contents. Addition of $0.5 \%$ of flakes showed reduction up to $5 \%$ for all three sizes of flakes. For $1 \%$ of flakes contents the strength reduced further up to $8 \%$. The maximum reduction at the dosage of $1 \%$ of flakes was noticed with $5 \mathrm{~mm}$ size. On further increasing the contents from $1 \%$ to $1.5 \%$ of flakes the strength reduced up to $39 \%$ in case of $5 \mathrm{~mm}$ size of the flakes. However the reduction in case of $1 \mathrm{~mm}$ and $17 \mathrm{~mm}$ sizes were $18 \%$ and $33 \%$ respectively. At a full dosage of $2 \%$ of flakes, the strength reduced up to $44 \%$ in case of $5 \mathrm{~mm}$ flakes. The reduction of strength in case of $1 \mathrm{~mm}$ and $17 \mathrm{~mm}$ size flakes was found to be $36 \%$ and $42 \%$ respectively. It was noticed that larger size of the flakes reduced the strength effectively. The aggregates covered with cement paste results in a better compressive strength. Inter molecular bonding of aggregates and cement paste results in strong adhesion and provides better strength. At the phase around the aggregate where coating of cement paste should be maximum get disrupted by the larger size of flakes. Additional the effective inter molecular friction which is essential for constituent adhesion also reduced due to the larger size of the flakes. In case of small size of flakes 
like $1 \mathrm{~mm}$ did not affect the overall molecular friction and showed less strength reduction.

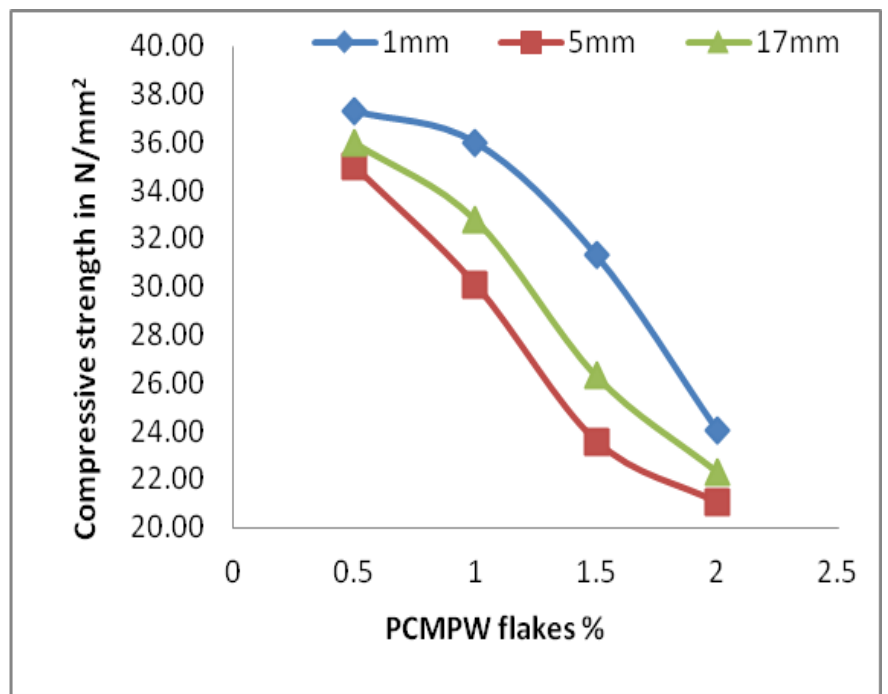

Fig.-4 Effects of PCMPW flakes on compressive strength

\subsubsection{Split tensile strength}

The split tensile strength reduced with the increased flake content and with varying size of flakes. However it was interesting to note that the split tensile strength increased for the flakes dosage up to $1 \%$ in case of $17 \mathrm{~mm}$ size flakes. This was an important finding form the study on the concrete response containing waste plastic flakes. The strength reduced up to $43 \%$ at full dosage of flakes for $1 \mathrm{~mm}$ size flakes at $2 \%$ addition and up to $47 \%$ in case of $5 \mathrm{~mm}$ size flakes at $2 \%$ of addition. The strength was increased up to $18 \%$ at $1 \%$ addition of $17 \mathrm{~mm}$ size flakes. The cement paste contains voids and internal micro cracks responsible for weak tensile strength of concrete. Addition of long size flakes in the concrete helped to improvise the tensile capacity of the paste and contributed to the better grip of paste on the constituents which resulted in the improved split tensile strength.

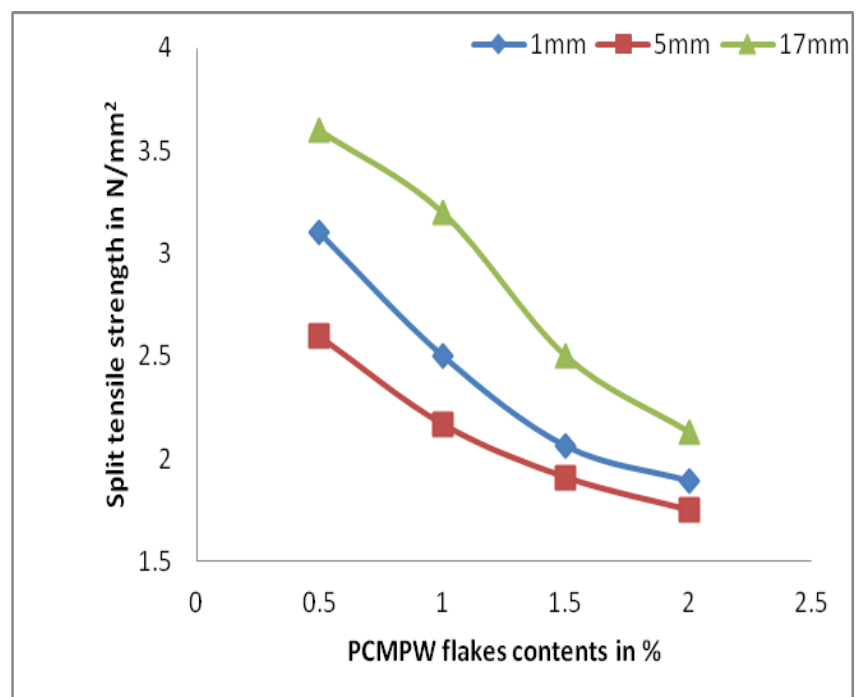

Fig- 5 Effects of PCMPW fakes on split tensile strength

\subsubsection{Relationship between compressive and tensile} strength

The relation between tensile strength and compressive strength of PCC can be expressed in form of power equation as $f_{\mathrm{t}}=\mathrm{k} *\left(f_{\mathrm{c}}\right)^{\mathrm{n}}$, where $\mathrm{k}$ and $\mathrm{n}$ are constants.

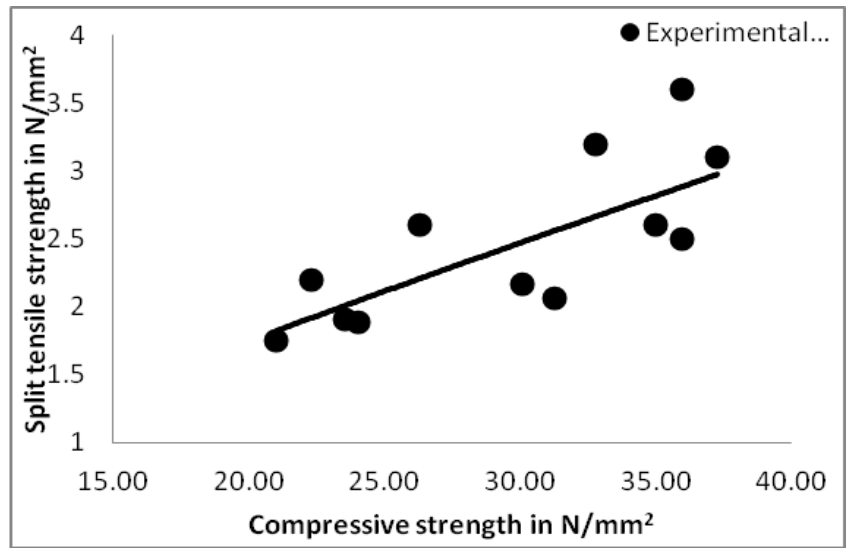

Fig-6 Split tensile - compressive strength relationship

As shown in figure 6, the experimental values of compressive-split tensile strength exhibited a power relationship as suggested by a standard relationship format. The analytical expression between split tensile strength $\boldsymbol{f}_{\mathbf{t}}$ and compressive strength $\boldsymbol{f}_{\mathbf{c}}$ was found as following,

$f_{\mathrm{t}}=0.14 *\left(f_{\mathrm{c}}\right)^{0.85}$

Different researchers have proposed different values of ' $k$ ' and ' $n$ ' which is mainly attributed to the difference in loading rates and constituents' proportions. Most commonly adopted relationships between tensile and compressive strength are as follows,

Neville equation [1]: $f_{\mathrm{t}}=0.23 *\left(f_{\mathrm{c}}\right)^{0.67}$

ACI 318-08 code $[2] f_{\mathrm{t}}=0.56 *\left(f^{\prime}{ }_{\mathrm{c}}\right){ }^{0.5}$

By employing the above standard equations on the Experimental results the graphs were developed as shown in figure 7 .

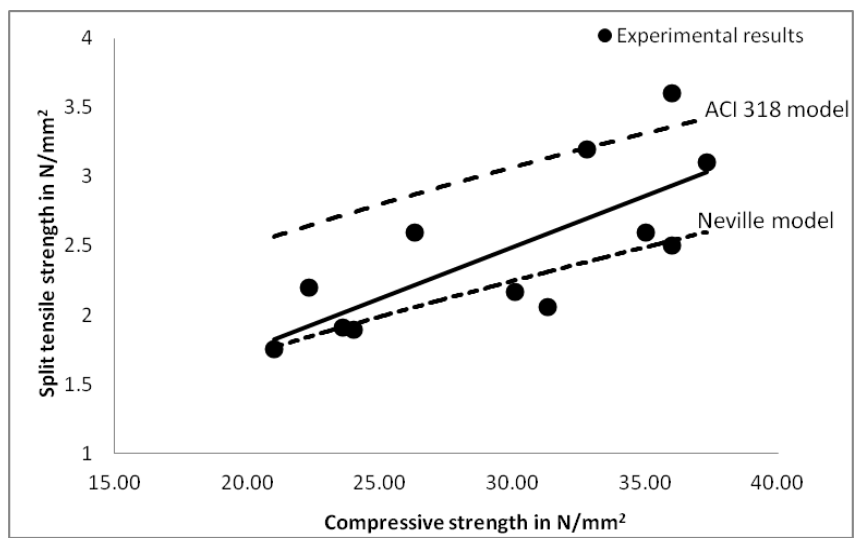

Fig- 7 Comparison of test results with standard models 
From the figure 7 , it could be observed that none of the existing analytical relationship was found suitable to predict the compressive-split tensile relationship. Neville equation (B) provided less reduction in the split tensile strength based on the compressive strength value compared to the ACI 318 (C).

The crack phenomenon in the concrete under compression has remained dependant on more than a single factor or variable. It has been found generally that the tensile strength of concrete depends on the compressive strength of the mix. However, the tensile resistance could be improved by improvising the ductility of the hydrated cement paste as observed from the work done on fibre reinforced concrete. Addition of plastic waste flakes contributed to the improved tensile resistance of the cement paste and provided better split tensile strength to the concrete.

The analytical model shown in (A) exhibited by the experimental values, suggested that compared to the standard relationship models the experimental values were found higher in case of the power term of the equation. Similarly the scale factor as prefix in the equation found to be lower than that of the standard models. The analytical relationship received from the experimental data, showed that the concrete containing PCMPW flakes showed better resistance to cracking in concrete compared to the conventional concrete. Moreover, the standard relationship counted the split tensile strength of concrete very low which did not agreed with the experimental results of concrete containing PCMPW flakes as the resistance to cracking was improved for concrete containing PCMPW flakes.

\section{CONCLUSIONS}

Addition of waste plastic flakes in fibre form of $17 \mathrm{~mm}$ length significantly improved the split tensile strength up to the contents of $1 \%$ by volume. Flakes of size $5 \mathrm{~mm}$ and $1 \mathrm{~mm}$ reduced the compressive strength significantly up to $30 \%$ at full dosage of $2 \%$ and found not suitable for application. $1 \%$ of waste plastic flakes addition provided acceptable response of the concrete mixes for all test conditions in all sizes of flakes. The compressive - split tensile strength relationship obtained from the experimental results also supported the improvement of tensile resistance of concrete containing PCMPW flakes. Addition of metalized plastic waste found feasible in concrete as constituent and showed research potential towards sustainable construction material development.

\section{REFERENCES}

[1]. A. M. NEVILLE, Properties of concrete, Fourth edition, United Kingdom, Pearson Prentice Hall, 1995.

[2]. ACI Committee 318. Building code requirements for structural concrete (ACI318-99) and commentary (318R-99). Farmington Hills, MI: American ConcreteInstitute; 1999.

[3]. F. Pacheco-Torgal, Yining Ding, Said Jalali "Properties and durability of concrete containing polymeric wastes (tyre rubber and polyethylene terephthalate bottles): An overview", Construction and Building Materials 30 (2012),p- 714-724.
[4]. IS: 456:2000, Plain and reinforced concrete code of practice.

[5]. Marzouk OY, Dheilly RM, Queneudec M. "Valorisation of Post Consumer Waste Plastic in Cementitious Concrete Composites", PubMed, U.S.National Library of Medicine, National Institute of Health, vol. 27 (2), Issue-12, 310- May, 2006.

[6]. Naik T.R., Singh S.S., C.O.Huber, and B.S.Brodersen, "Use of Post Consumer Plastics in Cement Based Composites", Cement and Concrete Research, Science Direct, Vol. 26, Issue 10, October, 1996, p- 1489 1492.

[7]. Narayan Priya, "Analysing Plastic Waste in IndiaCase Study of PET bottles and poly bags", Lund University, Sweden, September, 2001.

[8]. Saikia Nabajyoti, De brito J, "Mechanical properties and abrasion behavior of concrete containing shredded PET bottle waste as a partial substitution of natural aggregate", construction and building materials, volume 52, 2014, p-236-244.

[9]. Zainab Z. Ismail, Enas A. Al - Hashmi, " Use of Waste Plastic in Concrete Mixture as Aggregate Replacement", Waste Management, Science Direct, Vol. 28, Issue 11, November, 2008, p- 2041 - 2047.

\section{BIOGRAPHIES}

Prof. Ankur Bhogayata presently - Associate professor and Head of department in department of civil engineering at Marwadi Education Foundation Group of Institutions at Rajkot. He bears 12 years of academic experience. Currently pursuing his Ph.D.

Dr. N.K.Arora - presently the Principal of L.E. engineering collage, Morbi. He has more than 23 year of academic experience and has published half a dozen of text books. His areas of expertise are concrete technology, CASAD and sustainable materials.

Prof. Abhay Nakum is an assistant professor in department of civil engineering at Marwadi education foundation, Rajkot, Gujarat, India. He posses two and half year of teaching experience and pursuing his Ph.D in the area of sustainable construction materials. 